\title{
Evaluating the effects of resources and solvability on burglary detection
}

\author{
Timothy Coupe \\ Institute of Criminology, University of Cambridge, UK
}

\begin{abstract}
:
This study examines the effects of police officer resources and incident solvability, or the ease with which offences may be solved, on burglary detection. It is based on data from computerised police incident logs and self-completed surveys of officers. Findings indicate that the application of resources to the investigation of solvable incidents helps explains detection levels. Solvability characteristics determine whether burglaries may be solved, but successful detection is contingent on resource inputs, which enable detection potential due to solvability to be realised. Resources appear to be more cost-effectively used in earlier investigative stages than in detectives' further investigations. Better solvability predictors of 'intermediate outputs' and of the promising cases for further investigation by detectives, would enable resources to be more cost-effectively allocated. Findings differ from those of earlier studies in so far as large resource inputs raise detection rates for high solvability cases while some low solvability offences are solved, indicating that not all low solvability cases should be screened out by triage.
\end{abstract}

Key words: burglary, solvability, resources, burglary detection

\section{INTRODUCTION}

The objectives of this paper are to assess the effects of offence solvability and the resourcing of police activities on domestic burglary detection, and provide insights into how this information may be used to target and monitor the cost-effective use of police effort. Solvability, or how easily offences can be solved and whether they can be solved, depends on offence characteristics and affects detections ${ }^{1}$ or case clearance (Greenberg et al. 1977; Eck 1983; Frank and Brandl 1994). Burglary incidents possess characteristics that make them more or less likely to be solved (e.g. Greenberg et al., 1977; Eck, 1979; Eck, 1983), but this also requires resources or investigative effort from police officers. The premise is that burglary detection depends on offence solvability, but only to the extent that investigations are adequately resourced, so that detecting burglary depends on the appropriate resourcing of solvable offences. Cost-effective detection depends on this and not allocating resources to unsolvable cases, so that realising the full potential for detecting burglary depends on resourcing police activities at levels sufficient to meet investigative demands of cases it is possible to solve. The alignment of resources with incident solvability, it is argued, provides the key to explaining burglary detection. Without understanding the resourcing-solvability interactions that underpin investigative success, it is difficult to know how far shifts in resource allocation between strategies would improve performance, and how far, it is solvability or levels of overall resources (Ahlberg, 2002) that limit success in solving crime. Determining thresholds for screening cases for investigation is controversial, and this study may help throw light on the cases, in terms of solvability, to which resources may be directed to cost-effectively produce detected cases, and the effectiveness of resource use in different investigative stages.

Resources include labour, buildings, vehicles and other equipment, including forensic materials and technical and electronic devices. Labour, however, accounts for $80 \%$ or more of policing costs in developed countries, and officer time resource inputs into different activities are used to measure policing effort in this study. Police activities are defined as the actions or events that use resources to produce detection outcomes. Resource use can vary substantially for the same investigative activities, with different amounts of time spent questioning witnesses or suspects (Brandl and Frank 1994) or large variations in numbers of officers or units engaged in patrol responses at different incidents (Coupe and Blake 2005). Forensic resources are important for crime detection (Tilley\& Ford,1996; Bradbury \& Feist, 2005). They involve a labour element for collecting and processing samples, and the technical equipment and investigative capability provided by forensic analysis techniques, applied to various imprint, body, or 
chemical materials (Newburn, 2007) and equipment left by offenders at the scene, which affect case solvability.

This paper considers the ways resources and solvability combine to influence detection outcomes using data on first officer activities and further investigation by detectives of a sample of residential burglaries from first response by patrol officers until cases are detected or filed as undetected. The data also enable insights into the relative cost-effectiveness of various investigative activities. Supply of officer resources and crime demand are key inputs to the 'workload-detection' theoretical model (e.g. Tilley \& Burrows, 2005), in which changes in either input modifies detection outcomes. This paper aims to incorporate offence solvability into this model in order to assess the relative importance of matching resources to demand due to offence solvability in framing burglary investigation and detection. Therefore, an important aim in this paper is to understand and develop this theoretical aspect of crime detection, as well as provide some lessons for practical policing.

\section{Burglary 'solvability'}

\section{EXISTING RESEARCH}

Burglary solvability studies have identified offence characteristics associated with arrest, charge, case clearance or detection. All outcome definitions indicate an offender has been caught. Their aim has been to identify the solvability characteristics of cases that are most likely to be detected in order to inform case investigative screening decisions. In pointing to the cases most and least likely to be detected, solvability characteristics also provide an explanation of why cases are solved and, if resource inputs are also measured, provide the bases for assessing the importance of resources and offence solvability in accounting for detection outcomes, and determining the cost-effectiveness of investigative procedures, the objectives of this study. Assessments of offence solvability based on officer experience dominate current practice (Robinson \& Tilley, 2009). They may be in line with solvability factors identified from statistically-based screening, but, at best, are likely to be less rigorously applied. Solving burglary, it is argued, will reflect the degree to which officers' allocation of resources to investigative activities matches the potential solvability of offences. In practice, however, factors, such as staffing resource shortages, are likely to hamper the alignment of resources and solvability.

There have been solvability studies of burglary and robbery (e.g. Greenwood and Petersilia, 1975; Greenberg et al., 1977; Eck, 1979; Eck, 1983; Brandl and Frank, 1994) and other high volume offences. Both 'solvability' and 'crime clearance' studies identify incident characteristics which indicate certain sorts of cases are more likely and others, less likely to be solved. Both point to variations in solvability within crime types. Better evidence means cases are more easily solved than when cases have weak evidence, which are difficult or impossible to solve (e.g. Eck, 1983; Brandl and Frank, 1994). Selected incident characteristics make burglaries more solvable, predicting 67-92\% (Greenberg et al., 1977), and 86\% (Eck, 1979) of burglary case outcomes with $13 \%$ of cases screened in as having characteristics that justified investigation (Eck, 1979). On-scene capture and suspect identity information are characteristics most likely to result in arrest for residential burglaries (Greenwood, 1975; Eck, 1979; Eck, 1983; Coupe and Griffiths, 1996; Burrows et al., 2005; Paine \& Ariel, 2013), non-residential burglaries (Coupe and Kaur, 2005; Burrows et al., 2005), robbery cases (Newiss, 2002) and theft from and of motor vehicles (Burrows et al., 2005). For metal theft from railways, metal type, on-scene capture and scrap metal dealer visits were the strongest solvability factors (Robb, et al., 2014). Stronger suspect evidence, especially named individuals and eye-witness descriptions of a quality that enables matches to be made with known offenders, also produces more arrests in follow-up investigations (Issacs, 1967; Brandl and Frank, 1994). While Eck (1979) and Burrows et al. (2005) found usable finger-print evidence to be a weak predictor of detection, other residential burglary studies show foot-marks (Donnellan, 2012), finger-prints and DNA (Donnellan, 2012; Paine \& Ariel, 2013) to be important.

Therefore, markedly different levels of solvability are associated with different burglary characteristics, so that detection is far more likely for some offences than for others. This means that solvability factors from one set of incidents can be used to predict case outcomes for another (Eck, 1983; Paine \& Ariel, 2013). Solvability perceptions inform decisions about officer resource allocation to patrol responses and 
investigative activities. Therefore, offence characteristics influence solvability and officers' assessments of this help determine resource allocation priorities (Coupe, 2014; Paine \& Ariel, 2013; Robb, et al., 2014). Resourced activities lead to the evidence and arrests that enable case detection. Given imperfect knowledge of case solvability and reliance on experience-based solvability assessment (e.g. Robinson \& Tilley, 2009), which may not always be systematically applied, the potential of some solvable cases may not be fully exploited, while resources may be spent on less solvable ones, including those which police services must generally attempt to solve (e.g. Eck, 1983; Brandl and Frank, 1994; Klinger, 1997; Jansson, 2005). These include crimes involving vulnerable victims, such as distraction burglaries. These are commonly daylight offences involving elderly householders who, despite meeting offenders, are rarely able to provide suspect descriptions that lead to arrest (Coupe \& Blake, 2006). Mis-application of resources may also reflect workload variation, which results in resource shortfalls and surpluses (Coupe \& Blake, 2005).

\section{Resources and crime investigation}

Evidence regarding the role of resources in solving burglary or other crimes is less conclusive. Some studies do not measure effort directly or consider only a specific investigation stage, while others do not take account of solvability (e.g. Ostom, 1976; William \& Sunrall, 1982) or consider only a particular aspect of it, given different objectives. Studies that use individual offence data to specifically examine the relationship between resources and detection have invariably concluded that effort or resources have a strong effect on case detection, whereas the findings of aggregated data studies differ, with resources associated with detection in the U.K. but not in North America.

Eck's $(1979 ; 1983)$ studies used individual data and investigative activities as a measure of effort. His 'triage hypothesis' identified unsolvable weak cases, cases with strong evidence solved with little effort, and those with moderate evidence solved with sufficient additional effort (Eck, 1983). For follow-up burglary and robbery investigations using suspect evidence, Brandl and Frank (1994) found that more detectives' time was spent on cases with moderate than weak evidence, and the least time on cases with strong suspect evidence, while twice the time was spent on cases where an arrest was made. Their study, however, excluded the majority of cases, which had evidence so weak that the police screened them out prior to further investigation. Additional patrol resources boosted on-scene arrests most at more solvable inprogress burglary incidents (Coupe and Blake, 2005): lighter demands placed on beat patrol resources enabled stronger patrol responses by more units, and most on-scene arrests occurred when these coincided with highly solvable incidents, providing direct confirmation of the twin roles of solvability and resources. This is consistent with Tilley \& Burrows' (2005) finding, that every additional 10 property offences (consisting of burglaries, thefts of or from vehicles) per officer lowered detection rates by $1.5 \%$.

In England and Wales, aggregated data studies ${ }^{2}$ conclude that there are strong associations between officers per offence and case detection rates for the 43 Police Forces (Audit Commission, 1993), and the 278 basic command units or BCUs in place at the time of the study (Burrows, et al., 2005). In contrast, most studies of North American police jurisdictions suggest, at best, a weak relationship between indicators of resource levels and case clearance (Roberts, 2008; Ousey and Lee, 2010), although Chaiken (1975) found higher investigative workloads depressed detection rates. This may reflect the fact that most US research has been of large cities with resource shortages and heavy workloads, whereas the jurisdictions of many UK forces incorporate suburban and nearby rural areas. However, it also appears possible that North American studies may mask measurement of workload-detection relationships with other correlated measures like force size, community size (Paré et al., 2007), crime type (Paré et al., 2007), crime numbers and rural-urban jurisdiction (Cordner, 1989), logged population size and number of 'event history incidents' (Roberts, 2008), since larger forces are to be found in larger cities, which have more crime and poorer resources (Cordner, 1989; Klinger, 1997). Welford and Cronin's (1999) analysis of different police forces also found a weak relationship between workload and case clearance, but was confined to large cities, with a narrower range of crime profiles and workloads than studies with varied police jurisdiction sizes, especially if these include rural forces (Cordner,1989).

In addition, the presence of significant associations between resources and detections in UK studies and the lack of them in North American studies may partly reflect greater funding variation in the U.K. where different forces receive markedly different resources per crime. Staff supply relative to demand in English 
police forces ranges between 14 and 37 officers per 1000 crimes a year (Audit Commission, 1993). Resourcing is poorly aligned with crime incidence, and is even less likely to match solvability, so that police capacity to clear crime will substantially vary between jurisdictions. Even where well matched to overall demand within forces, resources can be poorly matched to solvability and to fluctuating crime levels and types across the day in U.K. (e.g. Coupe and Blake, 2005) and Sweden (Johansson, 2013). Large variations in resource and poor matching of resources to offence numbers and solvable offences offer a plausible explanation of detection rate variation in England and Wales.

Despite providing valuable insights into solvability, resources and detection, few, if any, studies have measured the relative effects of resources and offence solvability on arrest, clearance or detection of individual incidents using a measure of officer effort that incorporates time spent on first response, activities at the scene, further investigation by detectives through to cases being filed as detected or undetected. The association between solvability and detection outcomes may reflect partly the role of resources, which can be partly 'perceived' and may, for instance, include motivational factors. These issues are addressed by examining individual residential burglary data. The findings of this study will be evaluated in terms of Eck's (1983) and Brandl \& Frank's (1994) finding that more highly solvable cases demand fewer resources, and that low solvability cases are difficult, if not impossible, to solve, and medium solvability cases may be solved only with substantial resources. The extent to which the evidence from this burglary sample fits this three-category solvability-resource model will be assessed for evidence collected from first officers' activities at the scene, for further investigations by detectives and, overall, for the whole burglary investigation process. Claims (Eck, 1983; Paine \& Ariel, 2013) that little more than $13 \%$ of burglaries are solvable will also be critically evaluated.

\section{RESEARCH METHODOLOGY}

\section{Research design \& instruments}

Research was undertaken in 1994 in two divisions of a large U.K. city police force to understand how the police detected burglaries, how detected cases differed from undetected ones and the relative costeffectiveness of different policing activities. Individual data from self-completed questionnaire surveys of patrol response officers and from detectives at the stage in the investigation when offenders were charged or cases were filed as 'undetected' were collected for a single sample of residential burglary incidents. These were complemented by police records, including computerised response logs, with information about burglary reporting and response times and how the first officers at the scene dealt with each incident, and its outcome.

A random sample of 695 cases was drawn from 5768 burglaries that took place during a six month period. The response rate for the questionnaires completed by police officers was over $80 \%$, so that the final sample size is 573 cases. An offender arrested and charged is used to define a detected case ${ }^{1}$.

The sampling frame of two city divisions has a population of about three quarters of a million people and includes a variety of residential environments from inner city to outer suburban that provide residential properties of varied types and levels of risk to burglars. This suggests that findings should be generalisable to burglaries in other large urban areas, if not to those in villages and market towns, since similar solvability factors feature in rural Oxfordshire burglaries (Paine \& Ariel, 2013). The exception is that, in Oxfordshire, as in Manchester city (Donnellan, 2011) forensic evidence plays a rather greater role than in this study and others (e.g. Robinson \& Tilley, 2009; Tilley, et al., 2007), an issue considered below.

\section{Data}

Data were collected for each individual burglary incident on victims, dwelling circumstances, and incident characteristics which affect case solvability, and details of police officer time devoted to different activities, used to measure resource use. Police computer logs provided data on burglary incidence, who reported the offence, dwelling occupancy, and whether offenders were spotted at or near the scene. They also provided data on reporting and response times, numbers of officers responding, time spent at the scene questioning victims and their neighbours, and whether scenes of crime officers (SOCOs) examined burglary scenes. Questionnaires, self-completed on the shift that the burglaries occurred by first response officers, included 
details of dwelling occupancy at the time of the offence, when the victim had left the dwelling, means and points of dwelling entry and exit, numbers of rooms searched, stolen property, whether burglars had been disturbed. Information on whether victims and neighbors were questioned, suspect and suspect vehicle evidence, and whether SOCO visits occurred, was also elicited. Where officers completed questionnaires, there were relatively few incomplete questions, with 582 cases with data on whether suspects were disturbed, 577 and 574, respectively citing points of entry and exit, 579 with details of stolen property, 547 for victim age, and 567 indicating whether or not neighbours were questioned. Given uncertainties as to the time of the burglary event at some unoccupied dwellings, daylight / darkness data could be specified for 492 cases. Excepting daylight/darkness data, there were 573 cases where the majority of questioned were answered. Sample sizes for tests vary according to the combination of variables included, as indicated in the tables. Questionnaires completed by detectives when cases were solved or filed as undetected covered subsequent investigations, including visits to crime scenes, stolen property traces, crime pattern analysis, informant sourced information, forensic matches, surveillance and estimates of the time spent on each activity for every case. It is possible that some officers' time estimates were less accurate than others, although there were few outlying values for any individual investigative activities, and these were verified with officers and, if necessary, adjusted.

\section{Defining \& measuring resource use}

Resources are measured in terms of police officer time expended. This includes the total amount of time involved in responding to burglary incidents, based on the number of patrol officers and response times, the time spent by first officers carrying out investigations at the scene, and detectives' time. Amounts of time that first response units are 'idle' or engaged in other patrol functions are not factored into the measure of response time used in this study. Nor is back-office support or call centre staff time incorporated, but this is assumed to be an overhead that is proportionate to the amount of warranted officer time expended. As SOCOs attend crime scenes separately, no measure of time spent they spent at each burglary scene is available. Incorporating measures of these might modify the conclusions made about resource inputs and cost-effectiveness.

\section{Strengths and limitations of data}

The use of 1994 data is justified by its unique type and quality. The data are for individual offences, and there are time records for every police activity throughout the investigation process from patrol response, first officers' activities at burglary scenes and detectives' investigative tasks. The sample size is substantial and response rates of $80 \%$ for officer questionnaires for first officers and detectives are high, partly a reflection of a respected senior police officer who secured the involvement and commitment of local police area commanders, and a diligent and personable research associate who attended every shift and was known to most rank and file officers. Most studies of individual offences have not measured resources, but Eck $(1979 ; 1983)$ used police activities as a measure of effort. Only a single study, Brandl \& Frank's (1994) has used officer time to measure labour resources input to case investigations, but this covered only detectives' investigations, not patrol responses or first officers' activities at crime scenes. Other studies (e.g. Burrows, et al., 2005; Robinson \& Tilley, 2009) have used officer numbers as a resource measure, but there is no published research measuring labour spent on different activities at different investigative stages using individual offence data. Since the few UK police forces that have recorded time spent by individual officers on specific activities for individual offences, implement this inconsistently and intermittently, it appears very unlikely that there will be a dataset of comparable accuracy and completeness available unless considerable funding is directed at a dedicated study that replicates this one. It can, however, be difficult to gain access to police force data and organise a study that adds to officer workloads.

The study's findings also have a contemporary value owing to the relatively few changes in investigating and detecting burglaries during the last 20 years and the not dissimilar pressures being placed on staffing resources. UK forces are currently absorbing large funding reductions, while1994 was the year that UK crime peaked and when the Force providing the data for this study had insufficient resources to meet demand, making it unlikely that all solvable case investigations, then as now, could be adequately resourced. Cases are still screened using procedures not grounded in statistical measurement (Robinson \& Tilley, 2009) and the principal ways of solving them have altered little, with catching burglars red-handed 
or on the basis of eye-witness evidence about suspects still dominant (Tilley, et al., 2007, Robinson \& Tilley, 2009 cf. Coupe \& Griffiths, 1996). Few are solved now, as previously, by tracing stolen property, vehicle registrations, or by using informants.

Furthermore, despite increases in the use of proactive policing approaches (Newburn, 2007), these appear to be more effective for crime prevention (Tilley, et al., 2007). They play little role in the investigation of burglary and other high volume crime, most of which is still dealt with reactively (Jansson, 2005; Tilley, et al., 2007; Robinson \& Tilley, 2009; Donnellan, 2012; Paine \& Ariel, 2013). Examples of proactive policing of burglary include using informants for crimes to be subsequently committed, using under-cover officers for opening a false stolen property 'fence' to intercept offenders, or installing silent $\&$ delayed audible alarms (e.g. Pease, 1995) at premises in order to catch repeat offenders. Now, as in 1994, these appear to be of little importance in solving burglary.

One notable change, however, has been increased use of forensic evidence, which in the most recent studies accounts for a notable minority of detected cases (Donnellan, 2012; Paine \&Ariel, 2013), rather than, as formerly (e.g. Coupe \& Griffiths, 1996), as supporting evidence. This reflects the increasing sophistication of DNA evidence coupled with reduced testing costs that more often justifies its use for high volume offences like burglary. DNA and fingerprint evidence are powerful solvability factors with a strong effect size, but occur less often (Paine \& Ariel, 2012), and so remain less important factors for detecting burglary. Compared with the sample used in this study, nevertheless, this can be expected to increase the volume of cases in which forensic evidence plays a role in detection, alter the proportions of offences that are 'solvable' and, thereby, increase overall detections somewhat. While 'car-key' burglary has become more common with improved car security, accounting for $6 \%$ of E\&W burglary-dwelling incidents in 2008, most of these burglaries are also solved by rapid patrol responses or witness evidence, though vehicle registrations feature as evidence (Carden, 2012).

While other research has been published from this data set (e.g. Coupe \& Griffiths, 1996; 1999; 1999; Coupe \& Blake, 2006), the impetus for the current study was the development of a resourcing-solvability theoretical model between 2004 and 2007, which only recently has been fully documented (Coupe, 2014). An earlier paper based on this data set (Coupe \& Griffiths, 1996) used time measures selectively to indicate cost-effectiveness for particular investigative activities, but did not consider resource use throughout the investigative process, nor was solvability measured and related to time-resources, as in this study.

Papers dating from between 1967 and 1994, using older data sets than this study's, feature prominently in this paper's literature review because they are key research items, having been supplemented by only a few recent solvability studies with individual data (e.g. Donnellan, 2012; Paine \& Ariel, 2013).

\section{Hypothesis testing \& analysis}

The principal research question is whether resources and solvability are both significantly related to detections and the level of significance, when tested together, and whether each factor accounts for a substantial amount of variation in detection outcomes. Results of regressions of detection outcomes and evidence outputs on burglary characteristics are principally important, not, as with previous studies (e.g. Greenberg, et al., 1975; Eck, 1983), for identifying individual solvability characteristics for use in investigative case screening, but rather for assessing their combined importance for explaining detection outcomes, the ways they affect detections, and how, with resource information, they may be used to monitor cost-effectiveness. The focus is, therefore, on improving understanding of theoretical aspects of explaining detections, rather than providing specific advice for practising police officers. While costeffectiveness is evaluated, this is used to illustrate the ways that resource and solvability information may be used to monitor resource use and how it may be tailored to maximize detection outputs, rather than to provide specific and precise substantive advice to inform burglary policing. This is a need that 1994 data can meet.

A premise is that officers allocate available time resource inputs to different activities on the basis of their assessments of the solvability characteristics of cases. The ways different amounts of resources are used to 
deal with cases of differing solvability determines whether burglars are caught at the scene and whether evidence is collected for solvable burglary cases, and, thereby, cases solved.

Case characteristics that officers identify as promising for investigation are largely the same as those that emerge as solvability factors from statistical analysis, since this is based on current investigative processes, and officers provided information on investigations. A number of additional solvability indicators, such as victim age, were identified inductively from empirical analysis. There is also a high degree of agreement among burglary studies with regard to solvability factors (e.g. Eck, 1979; 1983; Tilley, et al., 2007; Donnellan, 2011; Paine \& Ariel, 2013), and their relative importance for detection. However, there can be expected to be some divergence in the importance of solvability factors in different studies in terms of the volumes in which they crop up and in effect sizes, depending on resource constraints on investigating cases, and variations in case screening approaches: where there are fewer formal procedures and resource shortages, it is likely that some cases with more promising solvability factors will not be investigated, and a greater risk that effort may be input to cases with weaker solvability factors. This can be expected to produce varying degrees of mis-match between statistically- and non-statistically-based case screening and investigation. Furthermore, statistical analysis may reveal differences in the importance and costeffectiveness of investigations based on different solvability characteristics that otherwise would not be uncovered.

\section{FINDINGS}

The police response to and investigation of burglary occurs in two stages (Diagram 1), and this conceptual model frames the empirical analysis and findings. The first stage is driven by burglary characteristics, which influence solvability, and resource inputs. It consists of the initial patrol response, investigations at the scene, including first responding officers questioning witnesses and SOCOs (scenes of crime officers) collecting forensic samples. These produce intermediate outputs in the form of offenders caught in the act, and witness and forensic evidence (Diagram 1).

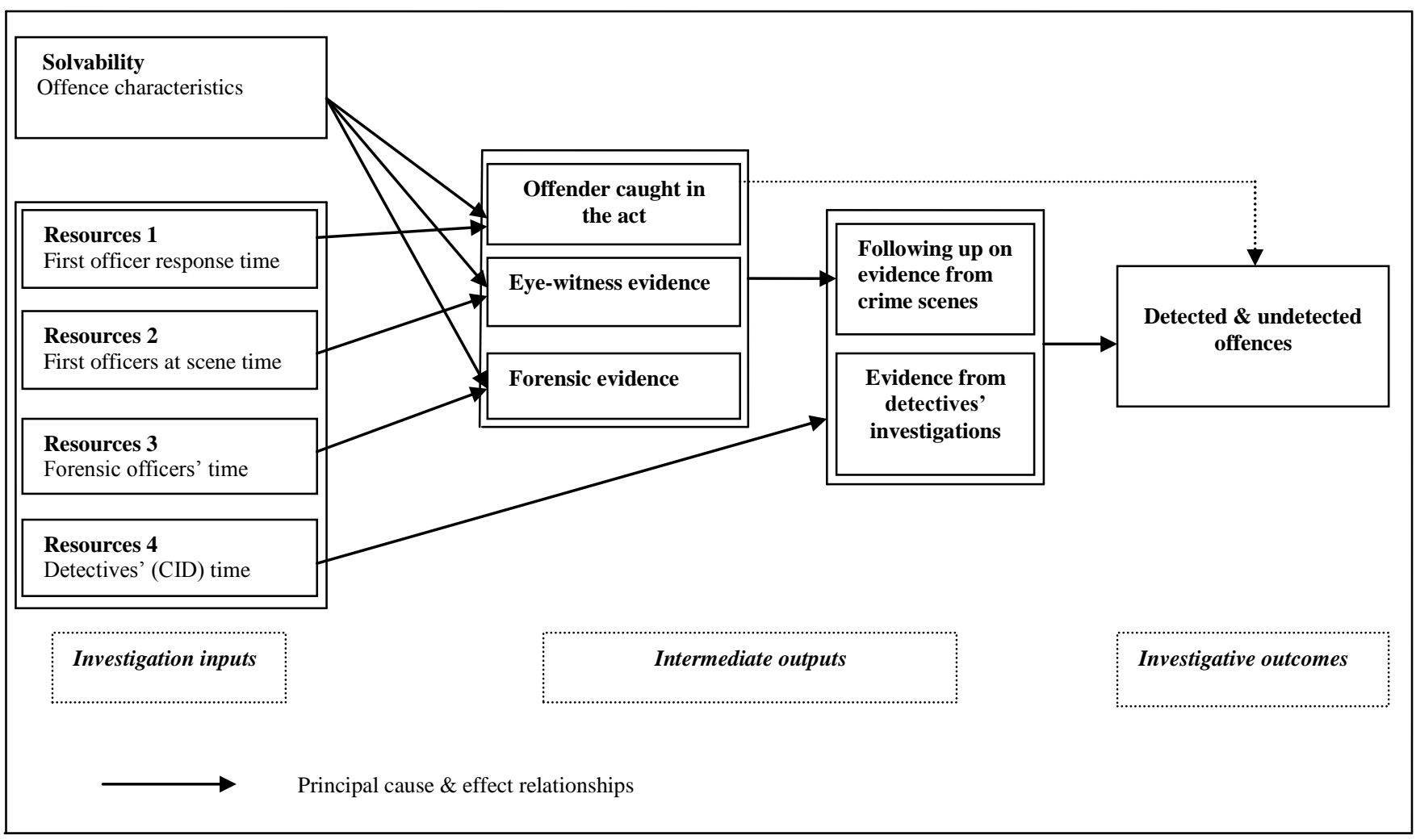

Diagram 1. The role of resources and solvability in reactive investigations of high volume crime 
The second stage involves detectives who use outputs from first stage activities, and undertake further investigation of selected cases to produce investigative outcomes, either detected or undetected cases. Their work includes matching suspect descriptions to known offenders, vehicle checks, collating forensic test results, tracing stolen property, visits to burglary scenes, surveillance activities, use of registered informants and burglary pattern analysis. Only a fifth of sample cases where burglars were caught at or near the scene were detected in the first stage, often as a result of being caught at the target; the rest, often where burglars were caught in nearby streets having jettisoned stolen property, required supporting evidence and further investigation. Hence, being caught at or near the scene is predominantly an 'intermediate output' which requires additional investigative effort to produce detected outcomes.

Analysis involves examination of: the effects of resource inputs and solvability on different intermediate outputs - offenders caught at or near the scene, witness evidence and forensic evidence; how these outputs plus any additional evidence arising from further investigations by detectives result in detected cases; the overall effects of solvability and resources on burglary detection; and a comparative evaluation of costeffectiveness across investigative stages. Binary logistic and ordinal regressions are used to investigate the association between resources and solvability co-variates, on the one hand, and intermediate outputs and detection outcomes on the other.

\section{Resource-solvability and catching burglars at or near the scene}

When controlling for response time resources, younger victims, burglar sightings, particularly those by neighbours and sightings at the time the burglary occurred were positively related to on-scene and nearscene capture (Table1). Response time, based on numbers of patrol officers and the sum of time they spent responding to each incident, also positively affected capture. Offender sightings while burglaries are in progress frequently receive 'immediate', rapid responses by more patrol units, as most available officers positively react, so that resource allocation will often be in line with the key solvability factor, except when incident demand exceeds patrol supply and reduces patrol availability (Coupe \& Blake, 2005). Sightings of vehicles, often used by older and more experienced offenders, were negatively related to capture.

Table 1. Binary logistic regression relating burglary characteristics \& travel time resources to burglar caught / not caught at or near the scene, the dependent variable

\begin{tabular}{lrrrrr}
\hline Variable & B & S.E. & Wald & Sig. & Exp(B) \\
\hline Younger victim (<65 years) & 1.137 & .417 & 7.448 & .006 & 3.118 \\
Suspect seen while burglary in progress & 1.692 & .361 & 22.002 & .000 & 5.430 \\
Suspect seen when leaving incident & .360 & .502 & .514 & .473 & 1.434 \\
Suspect seen / not seen by neighbour & .839 & .405 & 4.284 & .038 & 2.314 \\
Smashed entry into premises & -.297 & .289 & 1.063 & .303 & .743 \\
Suspect seen & .816 & .350 & 5.435 & .020 & 2.262 \\
Exited from front vs.rear or side & -.285 & .284 & 1.011 & .315 & .752 \\
Property stolen & .098 & .355 & .077 & .782 & 1.103 \\
Victim at home when burglarized & .279 & .348 & .643 & .422 & 1.322 \\
Number of rooms visited & -.039 & .280 & .020 & .888 & .961 \\
Vehicle seen & -1.48 & .582 & 6.479 & .011 & .227 \\
Entry by rear cf. front or side & -.110 & .365 & .092 & .762 & .896 \\
Burglar disturbed at the scene & .410 & .402 & 1.036 & .309 & 1.506 \\
Burglary occurred in darkness & -.231 & .271 & .725 & .394 & .794 \\
Travel time resources & .592 & .155 & 14.558 & .000 & 1.808 \\
Constant & -6.47 & 2.023 & 10.230 & .001 & .002 \\
\hline $\mathrm{n}=468$ (Cases omitted where daylight-darkness unknown) & & & & &
\end{tabular}

$36 \%$ of variation in on and near-scene capture/non-capture is accounted for by a combination of variation in response time resources and solvability characteristics (Nagelkerke $\mathrm{R}^{2}=.357$ ). When each independent 
was entered first into the regression, solvability had the greater influence over detection, though resources were also influential: resources accounted for $40 \%$ of explained variation (Nagelkerke $\mathrm{R}^{2}=.143$ ), solvability characteristics for $85 \%$ (Nagelkerke $\mathrm{R}^{2}=.303$ ).

Catching burglars at or near the scene and summary indices of solvability and resourcing

A summary index of solvability in terms of on/near-scene capture ('capture-solvability'), weighted according to the importance of each solvability factor, was calculated by summing the product of each significant burglary characteristic's binary value (e.g. burglar seen $=1$; not seen $=0$ ) and its logistic regression odds-ratio. The index provides a very accurate measure of capture-solvability (Nagelkerke's $\mathrm{R}^{2}=.966$, 'capture-solvability' index regressed on the significant solvability factors). This index measures solvability's effects on catching offenders at or near the scene, independently of the effects of time resource. This is a distinctive method of creating a summary measure of the independent variables in a regression that can have wide applicability.

Response time resources were only weakly related to capture-solvability index (Kendall's tau $b=.086$, $\mathrm{p}=.022, \mathrm{n}=481$ ), suggesting that resources were not closely applied to the most promising cases for on/nearscene capture. This hardly unexpected, since patrols were often unavailable to respond in sufficient quantity when demand was high, so that highly solvable incidents often only received strong patrol responses during periods of low workloads. Responses were also not being systematically graded and prioritised, so that more solvable incidents, in terms of catching burglars at or near the scene, did not, in any case, always receive a response that matched their solvability. As often as not, available nearby patrol officers called in to flag their proximity on hearing an 'in-progress' alert and then responded.

Table 2. Effects of capture-solvability and response time resources on on/near-scene capture

\begin{tabular}{|c|c|c|c|c|c|c|c|c|c|c|}
\hline & B & S.E. & Wald & Sig & $\operatorname{Exp}(B$ & B & S.E. & Wald & & $\operatorname{Exp}(B$ \\
\hline & & & & & ) & & & & Sig & ) \\
\hline $\begin{array}{l}\text { Capture-solvability } \\
\text { index }\end{array}$ & .225 & .030 & 55.83 & .000 & 1.253 & .284 & .067 & 18.03 & .000 & 1.329 \\
\hline $\begin{array}{l}\text { Response resources } \\
\text { index }\end{array}$ & .355 & .075 & 22.10 & .000 & 1.426 & .836 & .489 & 2.93 & .087 & 2.307 \\
\hline $\begin{array}{l}\text { Capture-solvability } \\
\text { v. response resource }\end{array}$ & & & & & & -.019 & .019 & 1.011 & .315 & .981 \\
\hline Constant & -7.34 & .751 & 95.49 & .000 & .001 & -8.84 & & 27.162 & .000 & .000 \\
\hline
\end{tabular}

Both capture-solvability index and response time resources significantly affect on-scene arrest, with strong effect sizes (Table 2). The interaction between capture-solvability and resources does not affect on/nearscene capture, and taking account of it enhances the independent effects of capture-solvability factors and response time resources (Table 2). It confirms that the use of patrol response resources is not closely aligned with the potential for on-near-scene capture. This is likely, as indicated, to reflect a dearth of patrols when demand is high and a surfeit when workloads are low when patrols may respond to 'in progress' burglaries with poor arrest prospects.

'Capture-solvability index' and resources were divided into high, medium and low categories, with equal proportions of sample cases in each. A combination of 'capture-solvability' and response time resources is needed to discriminate between incidents where burglars are caught and not caught at or near burglary scenes (Figures 1a,b). Additional resources raise capture rates for low and medium solvability levels, and medium-high resources appear essential for detecting all but the highly solvable offences. Equally, for similarly resourced incidents at each level, superior capture-solvability independently elevated capture rates (Figure 1b). A subset of cases of high solvability were detected, despite low resources (Figure 1a), a finding that is in alignment with Eck's (1983) and Brandl \& Frank's (1994) that high solvability incidents may be detected with fewer resources. These are incidents where burglars were unaware they had been sighted entering dwellings, providing time for single, often single-crewed patrols to intercept them before exiting. 
Figure 1a. Caught at/near scene rates for solvability groups for different patrol resource inputs

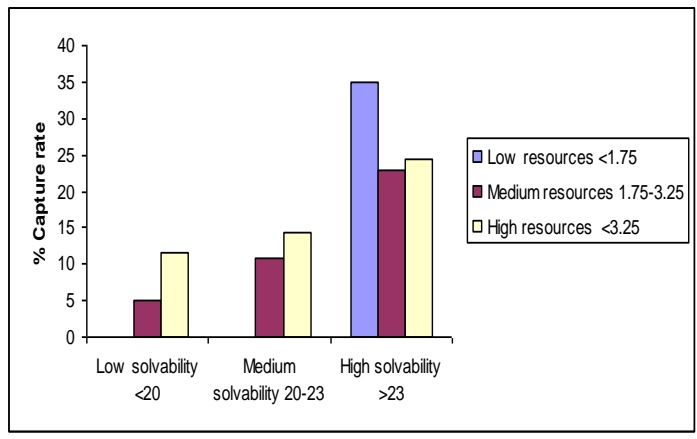

Figure 1b. Caught at/near scene rates for patrol resource groups by different solvability inputs

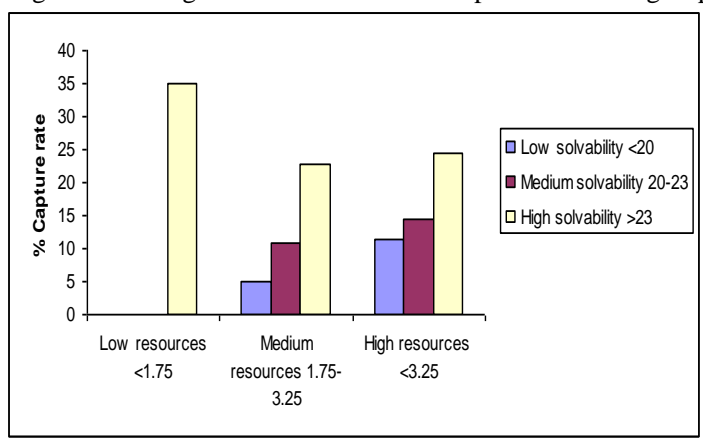

Findings confirm that resources are an essential element affecting the association between solvability and on/near-scene arrest (Coupe \& Blake, 2005): larger resource inputs generally boost arrests at incidents of all solvability levels, though the more solvable the incident, the greater the effect. That larger resource inputs boost arrests even at highly solvable incidents is not wholly consistent with the idea that more solvable incidents require fewer resources for detection (e.g. Eck, 1983). However, the comparable proportions of high 'capture-solvability' cases detected whatever the resourcing, does suggest there are some cases which may be solved with fewer resources.

\section{Resources, solvability and suspect evidence collected at crime scenes}

First officers at the scene questioned neighbours and victims who might be able to provide suspect descriptions or even suspect names. Suspect evidence was graded according to its quality: good quality descriptions, including named and positively identified suspects; medium quality, with descriptions implicating possible suspects; and poor quality, which includes less clear suspect descriptions, gender and approximate age information. Suspect vehicles may also attract the attention of eye-witnesses, who observe burglars arriving or leaving.

Taking account of time spent by first officers at burglary scenes, there was better quality suspect evidence when burglaries occurred during daylight, victims were younger ( $<65$ years) and, selfevidently, when suspects were seen. Poorer quality suspect evidence was associated with burglars spotted only when leaving the scene (Table 3 ). These were especially sightings attributable to victims after dark, when burglars tended to flee having realised properties were occupied. It accounts for better evidence when victims were not at home (Table 2) and when neighbours spotted burglars earlier in the burglary, often during weekdays.

The time first officers spent at the scene (Diagram 1, Resource2) and solvability characteristics and resources both had a strong positive effect on the quality of witness evidence collected, together accounting for $85 \%$ of variation in suspect evidence (Nagelkerke $\mathrm{R}^{2}=.845$ ). First officer time resources account for $33 \%$ of explained variation in suspect evidence collected there when entered first into the regression (Nagelkerke $\mathrm{R}^{2}=.276$ ), solvability characteristics for $99 \%$ (Nagelkerke $\mathrm{R}^{2}=.845$ ). Solvability is, predictably, the stronger influence on suspect evidence quality, since questioning of neighbours that 
turns out to be fruitless, for instance, is likely to take almost as long as where useful evidence is provided.

Table 3. Ordinal regression relating burglary characteristics \& first officer time at crime scenes to suspect evidence collected at the scene, the dependent variable

\begin{tabular}{lrrrrrr}
\hline Variable & B & S.E. & Wald & Sig. & $\begin{array}{r}\text { Lr 95\% } \\
\text { C.I. }\end{array} \begin{array}{l}\text { Ur } \\
\text { C.I. }\end{array}$ \\
\hline Older victim (>65 years) & & & & & & \\
Suspect seen & -1.18 & .382 & 9.487 & .002 & -1.927 & -.428 \\
Suspect seen by neighbour & 8.93 & .918 & 94.629 & .000 & 7.130 & 10.728 \\
Suspect seen leaving scene & -.009 & .368 & .001 & .981 & -.731 & .713 \\
Suspect seen when burglary in progress & .561 & .349 & 2.582 & .108 & -.123 & 1.245 \\
Exited from front $v$ s.rear or side & .086 & .325 & .070 & .791 & -.551 & .723 \\
Property stolen & .448 & .326 & 1.885 & .170 & -.191 & 1.087 \\
Victim at home when burglarized & .877 & .405 & 4.683 & .030 & .083 & 1.672 \\
Vehicle seen & -.381 & .441 & .748 & .387 & -1.246 & .483 \\
Entry by rear cf. front or side & .159 & .379 & .176 & .675 & -.584 & .903 \\
Burglary occurred in darkness & .595 & .302 & 3.873 & .049 & .002 & 1.188 \\
First officer time spent at scene & 1.223 & .322 & 14.377 & .000 & .591 & 1.855 \\
\hline
\end{tabular}

$\mathrm{n}=468$ (Cases omitted where daylight-darkness unknown)

Resource-solvability and forensic evidence collected at crime scenes

Few, if any, variables measuring burglary characteristics were related to useful (i.e. potential for a match to be established) forensic samples recovered from the crime scene. When tested in a binary logistic regression, only 'whether or not a burglary was reported while in-progress' was significant $(p=.019)$, accounting for less than $1 \%$ of variation in the dependent variable (Nagelkerke $\left.\mathrm{R}^{2}=.007\right)$. Whether victim was at home, property stolen, where target was exited, forced entry, search type (tidy/untidy), number of rooms visited, vehicle seen, suspect sighting, weekday-weekend, or daylightdarkness incidence were not significantly related to the collection of useful forensic evidence.

Examination of a small subset of detected cases for which offender details are available indicates that recovered forensic samples were collected where fewer items of property were stolen, burglars left by windows or doors at either the side or rear of the dwelling, and where offenders had committed more burglaries during the last year and charged for more burglary offences. That more forensic evidence is left by burglars who are caught more and who are more prolific is hardly surprising, but this does not point to the burglary scenes SOCOs should examine. Information on exit points and items stolen provide insufficiently specific pointers to scenes with forensic evidence. SOCOs visited $90 \%$ of burglary scenes and the effects of resources are difficult to estimate ${ }^{3}$.

\section{Relationships between resources, evidence and detections}

This section considers the effects of detectives' time inputs, evidence from detectives' further investigations and evidence from earlier, first stage activities on detections. Most witness and forensic evidence derives from the first policing stage as 'intermediate outputs' for incidents which need further investigation involving relatively small amounts of detectives' time. Other cases are allocated more time as detectives strive to collect additional evidence. Much evidence is the product of resources applied to first-stage policing activities, directed at solvable cases.

Controlling for time spent on further investigations by detectives, better quality suspect descriptions, the collection of useful forensic evidence, and catching offenders at or near the scene were significantly related to burglary detection outcomes (Table 4). Distinctive stolen property, vehicle registration plates and undertaking surveillance had no significant independent effects, despite being individually highly correlated with detected/undetected outcomes (distinct property: $\chi^{2}=6.98, \mathrm{p}=.008$; vehicle registrations, $\chi^{2}=11.75, p=.001$; surveillance: $\left.\chi^{2}=10.05, p=.002\right)$. Though these factors may contribute to detecting 
cases, they occur infrequently (c. $1 \%$ of the sample for vehicle registration \& surveillance, $2 \%$ for distinctive stolen property), so that low incidence makes their role inconsequential. Information collected by detectives who subsequently visited neighbours and victims to question them about the burglaries had no effect on solving cases. The time spent by detectives on further case investigation was, however, positively related to whether cases were detected.

Combined, evidence quality and resources account for $54 \%$ of explained variation in detection outcomes (Nagelkerke $\mathrm{R}^{2}=.539$ ). Detectives' time inputs account for $17.1 \%$ of explained variation (Nagelkerke $\mathrm{R}^{2}=.092$ ), when entered first into the regression, evidence for $95 \%$ (Nagelkerke $\mathrm{R}^{2}=.510$ ), with a far larger effect.

Table 4. Binary logistic regression relating evidence, on/near-scene capture \& detectives' time to detected/undetected, the dependent variable

\begin{tabular}{|c|c|c|c|c|c|}
\hline Variable & B & S.E. & Wald & Sig. & $\operatorname{Exp}(B)$ \\
\hline Caught/not caught at/ near scene & 1.433 & .257 & 31.110 & .000 & 4.192 \\
\hline Useful forensic evidence / none & 1.342 & .335 & 16.021 & .000 & 3.826 \\
\hline $\begin{array}{l}\text { Good suspect evidence cf. none }\left(I^{\text {st }}\right. \\
\text { officer })\end{array}$ & 3.530 & .504 & 48.976 & .000 & 34.139 \\
\hline $\begin{array}{l}\text { Quite good suspect evidence cf. none } \\
\left(1^{\text {st } \text { Officer })}\right.\end{array}$ & 1.770 & .328 & 29.068 & .000 & 5.871 \\
\hline $\begin{array}{l}\text { Poor suspect evidence cf. none ( } 1^{\text {st }} \\
\text { officer) }\end{array}$ & .591 & .348 & 2.882 & .090 & 1.807 \\
\hline Distinctive stolen property /none & 1.055 & .813 & 1.683 & .194 & 2.873 \\
\hline Vehicle registration plate / none & 2.014 & 1327.91 & .000 & .999 & 7.490 \\
\hline Surveillance /no surveillance & 1.995 & 1440.45 & .000 & .999 & 7.352 \\
\hline $\begin{array}{l}\text { Information/or not from detectives } \\
\text { questioning neighbours }\end{array}$ & .279 & .348 & .643 & .422 & 1.322 \\
\hline $\begin{array}{l}\text { Information /or not from detectives } \\
\text { questioning victims }\end{array}$ & -.693 & .988 & .493 & .483 & .500 \\
\hline $\begin{array}{l}\text { Dectectives collected / not collected } \\
\text { other sorts of new information (e.g. } \\
\text { informants) }\end{array}$ & 2.420 & 1.688 & 2.057 & .152 & 11.24 \\
\hline $\begin{array}{l}\text { New information collected / not } \\
\text { collected by detectives }\end{array}$ & -.905 & .927 & .953 & .329 & .405 \\
\hline $\begin{array}{l}\text { Detectives' time inputs into further } \\
\text { investigations }\end{array}$ & .063 & .021 & 8.712 & .003 & 1.065 \\
\hline Constant & -26.68 & 14404.46 & .000 & .999 & .000 \\
\hline
\end{tabular}

Evidence and Summary Indices of Solvability and Resourcing.

An 'evidence-solvability' index was calculated on the same basis as the 'capture-solvability' index, using odds-ratios from the regression in Table 4. This index is also a precise measure of offences' solvability in terms of evidence, (Nagelkerke's $\mathrm{R}^{2}=.982$, 'evidence-solvability' index regressed on the significant evidence solvability factors).

Table 5. Effects of evidence-solvability and detectives' time resources on detections

\begin{tabular}{|c|c|c|c|c|c|c|c|c|c|c|}
\hline & B & S.E. & Wald & Sig & $\begin{array}{r}\operatorname{Exp}(B \\
)\end{array}$ & B & S.E. & Wald & Sig & $\begin{array}{r}\operatorname{Exp}(B \\
)\end{array}$ \\
\hline $\begin{array}{l}\text { Evidence-solvability } \\
\text { index }\end{array}$ & .120 & .011 & 110.23 & .000 & 1.128 & .126 & .013 & 100.90 & .000 & 1.134 \\
\hline $\begin{array}{l}\text { Detective resources } \\
\text { index }\end{array}$ & .064 & .020 & 9.99 & .002 & 1.066 & .099 & .036 & 7.48 & .006 & 1.104 \\
\hline $\begin{array}{l}\text { Evidence-solvability } \\
\text { v. Detective resource }\end{array}$ & & & & & & -.002 & .002 & 1.667 & .197 & .998 \\
\hline Constant & -2.711 & .220 & 151.89 & .000 & .066 & -2.809 & .238 & 139.31 & .000 & .060 \\
\hline
\end{tabular}


Predictably, the independent effects of 'evidence-solvability' and detectives' time resources on detections were elevated when taking account of the interaction between them (Table 5), which did not itself independently help explain variation in detection levels. This reflects the small amounts of detectives' time needed to complete investigation of cases, often 'medium' solvability ones, where the key evidence resulted from the application of resources to earlier activities, notably response time and first officer time at the scene. The positive, independent effects of detectives' time indicate that effort spent on cases needing considerable additional investigation helps boost detections, even if they are achieved less cost-effectively.

Figure 2a. Detection rates for evidence-solvability groups for different detective resource inputs

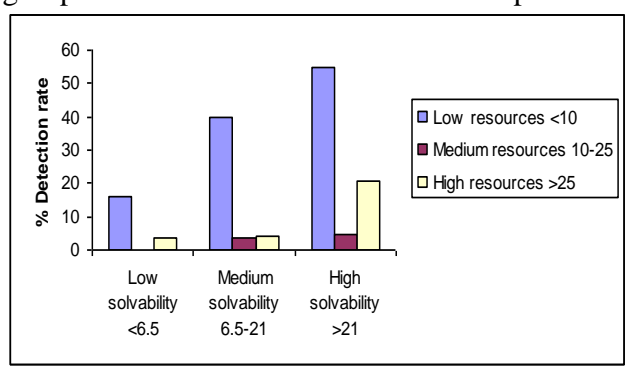

Figure $2 b$. Detection rates for different detective resource groups for different evidence-solvability inputs

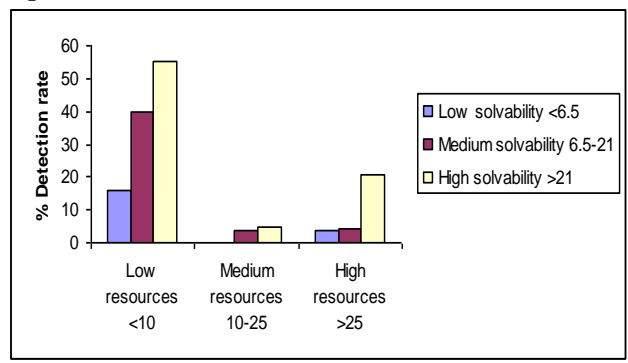

The 'evidence-solvability' index and further investigative resources were classified in terms of high, medium and low categories, with equal numbers of cases in each. Higher 'evidence-solvability' resulted in superior detection rates (Figure 3b) for every level of resourcing. However, detection rates were highest for cases with low resource inputs, and medium resourced cases had the poorest detection rates (Figure 3b).As indicated, this is because cases receiving low detective resource inputs were especially those with far better intermediate outputs from the first policing stage, which then require small amounts of further investigation by detectives. This included collating and matching suspect and forensic evidence to known offender records, and arresting offenders who had not already been taken into custody. More cases receiving low detective resources had good suspect evidence $\left(\chi^{2}=98.84,6 \mathrm{df}\right.$, $\mathrm{p}=.000)$, useful forensic evidence $\left(\chi^{2}=32.92,2 \mathrm{df}, \mathrm{p}=.000\right)$ and on/near-scene captures $\left(\chi^{2}=36.45,2 \mathrm{df}\right.$, $\mathrm{p}=.000) .62 \%$ of cases with low detective resources had one or more of these characteristics compared with $47 \%$ of cases allocated high amounts of detectives' time, but only $22 \%$ of cases allocated medium detective time resources. This is confirmed by the fact that detective time inputs are not related to evidence-solvability (Kendall's-tau_b=-.039, $p=.213, \mathrm{n}=568$ ), whereas response time resources (Kendall's-tau_b=.132, $p=.000$ ) and resources spent by first officers at the scene (Kendall'stau_b=.246, $p=.000$ ) are, albeit with small or medium effect sizes. It seems clear that lower resourcing of more solvable cases at the stage when detectives undertake further investigation, as identified by Brandl \& Frank (1994), is partly accounted for by prior higher resourcing of first officer activities, rather than simply more solvable cases needing fewer resources to be solved. High resources input to detectives' investigations, nevertheless, boosted detections for every solvability level (Figure 3a), even benefiting high solvability cases, which appears to be at odds with the idea that such cases demand fewer resources.

Additional cases were, therefore, detected as a result of high and low detective resource inputs, but quite substantial amounts of investigative resources were also directed at cases which were less solvable, received medium or high resource inputs and often remained unsolved. It appears that not all resources allocated to further investigations were used cost-effectively.

Hence, a high proportion of cases receiving small amounts of detectives' time were solved, since, with existing evidence, they needed little additional investigation. Many of these were where offenders were caught red-handed in the burgled dwelling. Although, on/near scene capture is one of the better predictors of detection, it includes many offenders caught near, rather than at the scene, notably in nearby streets, which were less easily detected and demanded further investigative inputs, especially if burglars jettisoned stolen goods. These cases lower solvability status of on/near-scene capture. 
The purpose of this section is to examine the overall relative effects of incident solvability characteristics and all resource inputs on detecting incidents.

A mixture of burglary characteristics and resource inputs help account for detection outcomes (Table 4). Burglar sightings, including those by neighbours, daylight rather than darkness, and younger victims (fewer than 65 years) are significantly related to detections. Whether a vehicle was seen, dwellings occupied at the time of the incident, property stolen, or whatever the burglary exit point had no significant effect on detection.

Together, resources and solvability characteristics explained $52 \%$ of variation in detections (Nagelkerke's $\mathrm{R}^{2}=.517$ ). Characteristics reflecting solvability appear responsible for a greater share of the effect, accounting for more explained variation in detections than resources when each was entered first (solvability: $78 \%$ of explained variation, Nagelkerke's, $\mathrm{R}^{2}=.402$; resources: $62 \%$, Nagelkerke's, $\mathrm{R}^{2}=.318$ ), with a minimum of $38 \%$ of explained variation attributable to solvability characteristics resources, and $22 \%$ to resources. Offence solvability is more important, though both play a substantial role in burglary detection.

Time inputs into patrol responses, time spent by first officers at burglary scenes and time spent on detectives' investigations all contributed to whether cases were detected. Detectives' investigation time appears to have been less cost-effective in raising detections than response time and first officers' time at the scene (Table 6).

Table 6. Binary logistic regression relating burglary characteristics \& travel time, officer time at scene and detectives' time to detected / undetected, the dependent variable

\begin{tabular}{lrrrrr}
\hline Variable & B & S.E. & Wald & Sig. & Exp(B) \\
\hline Younger victim (<65 years) & 2.153 & .458 & 22.102 & .006 & 8.609 \\
Suspect seen while burglary in progress & 1.624 & .425 & 14.585 & .000 & 5.074 \\
Suspect seen when leaving incident & 1.646 & .592 & 7.725 & .005 & 5.184 \\
Suspect seen / not see by neighbour & .668 & .449 & 2.213 & .137 & 1.949 \\
Smashed entry into premises & -.106 & .289 & .134 & .714 & .900 \\
Suspect seen & 1.276 & .382 & 11.136 & .001 & 3.582 \\
Exited from front vs.rear or side & -.285 & .284 & 1.011 & .315 & .752 \\
Property stolen & .243 & .391 & .387 & .534 & 1.275 \\
Victim at home when burglarized & .319 & .367 & .757 & .384 & 1.376 \\
Number of rooms visited & .256 & .292 & .767 & .381 & 1.292 \\
Vehicle seen & .498 & .593 & .707 & .401 & 1.646 \\
Entry by rear cf. front or side & .514 & .408 & 1.592 & .207 & 1.672 \\
Burglar disturbed at the scene & .035 & .471 & .005 & .941 & 1.035 \\
Burglary occurred in darkness & .583 & .274 & 4.526 & .033 & 1.791 \\
Travel time resources & .291 & .152 & 3.678 & .056 & 1.338 \\
Time first officers spent at scene & .528 & .174 & 9.235 & .002 & 1.695 \\
Detectives' investigation time & .068 & .019 & 12.803 & .000 & 1.071 \\
Constant & -17.16 & 2.536 & 45.803 & .000 & .000 \\
\hline n=468(Cases omitted where daylight-darkness unknown) & & & &
\end{tabular}

$\mathrm{n}=468$ (Cases omitted where daylight-darkness unknown)

Overall detections and summary indices of resourcing and solvability

As for 'capture-solvability' and 'evidence-solvability', a summary index of the 'overall solvability' of burglary cases, weighted according to the importance of each solvability factor, was calculated by summing the product of each case's significant burglary characteristic's binary value and its logistic regression odds-ratio (Table 6). A resource index, using odds-ratios for time spent for response, first officers at the scene and further investigation, was calculated on the same basis. These indices measure solvability's effects on solving cases, independently of the effects of time resource, and vice versa. Both are very accurate measures of overall solvability (Nagelkerke $=.991$, when index is regressed on 
significant solvability factors) and overall resource use $\left(r^{2}=.997\right.$, resources index regressed on travel time, first officer time at scene and detectives' time).

Table 7. Effects of overall solvability and overall time resources on detections

\begin{tabular}{|c|c|c|c|c|c|c|c|c|c|c|}
\hline & B & S.E. & Wald & Sig & $\begin{array}{r}\operatorname{Exp}(\mathrm{B} \\
) \\
\end{array}$ & B & S.E. & Wald & Sig & $\begin{array}{r}\operatorname{Exp}(\mathrm{B} \\
) \\
\end{array}$ \\
\hline Solvability index & .341 & .040 & 72.32 & .000 & 1.407 & .236 & .058 & 16.88 & .000 & 1.267 \\
\hline All resources index & .116 & .020 & 32.92 & .000 & 1.123 & -.300 & .168 & 3.19 & .074 & .741 \\
\hline $\begin{array}{l}\text { Solvability index v. } \\
\text { all resources }\end{array}$ & & & & & & .011 & .005 & 5.71 & .017 & 1.011 \\
\hline Constant & -15.271 & 1.650 & 85.69 & .000 & .000 & -11.229 & 2.225 & 24.795 & .000 & .000 \\
\hline
\end{tabular}

$\mathrm{n}=468$

In general, the more solvable the case, the higher the resource inputs (Kendall's tau $b=.266, p=.000$ ), though the effect size is moderate. The logistic regression of whether cases were detected on solvability index and resource index shows that both independently account for variation in case outcomes (solvability index: $p<.000 ; \operatorname{Exp}(\mathrm{B})=1.407$; resources index: $p<.000, \operatorname{Exp}(\mathrm{B})=1.123$ ), with the stronger effects of solvability confirmed (Table 7).

The interaction between overall solvability-index and resource index is positively related to detection, indicating that the application of resources enables the realisation of detection potential presented by solvability characteristics. Independently of it, solvability and resources retain effects on explained variation (Table 7), but, in the case of resources, these lower the odds of cases being detected. It is likely that this reflects the application of resources to less solvable cases, which remain undetected. The strong effects of solvability on detection, independent of its interaction with resources, indicate that, irrespective of resource inputs, higher solvability results in more detected cases: this confirms that some high solvability cases, for instance, may be solved with differing amounts of resources, while resources are over-invested in some poorer solvability cases. These include unjustifiably strong patrol responses, fruitless questioning of neighbours, or further investigations that fail to result in case detection.

Figure 3a. Detection rates (percentages) for resource groups for different solvability inputs

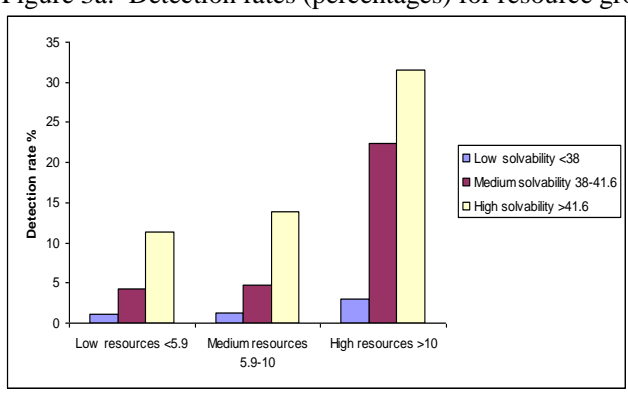

Figure 3b. Detection rates (percentages) for solvability groups for different resource inputs

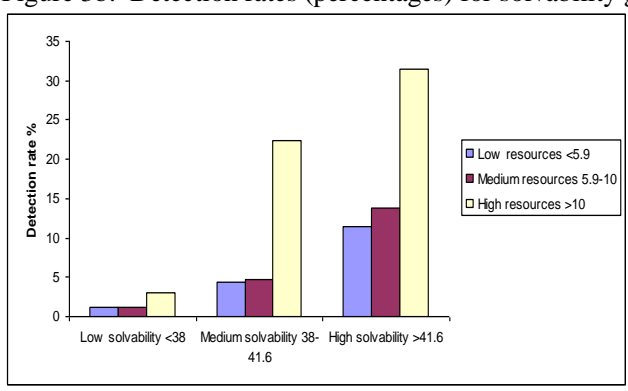


When 'overall solvability' and resources indices were divided into high, medium and low categories with equal case numbers, both co-vary with detection (Figure 3a,3b), so that both are needed to discriminate between detected and undetected cases. Additional resource inputs elevated the proportion of detected cases for every solvability level (Figure $3 \mathrm{~b}$ ). Principal improvements resulted from higher resource inputs, with the most striking rises due to the input of high resources to cases of medium solvability (Figure 3b), for which improved detection rates were gained most cost-effectively. Equally, higher solvability improved the prospects of detection for every level of resourcing (Figure 3a), so that, to some extent, highly solvable cases return improved detection outcomes, irrespective of resourcing, while low solvability offences produce poor detection rates whatever resources are allocated. Cases combining high solvability and high resources had the best detection rates. Conversely, those with the lowest resource-solvability combination had the worst (Figure 3a,3b). Nevertheless, high resources applied to high solvability cases did boost detections, while some low solvability cases were detected. These findings are at odds with earlier studies which found that high solvability incidents required fewer resources to detect (Eck, 1983; Brandl \& Frank, 1994) and that low solvability cases were impossible to solve, whatever the resources, and should be screened out comprehensively using 'triage' assessment (Eck, 1983). Given their large numbers, success in detecting low solvability cases indicates a higher potential for solving burglary, while 'following the evidence' in cases that do not meet high solvability standards, statistically, can evidently be effective, the more so if indicators for them can be eventually found.

In the light of detection levels reached by inputting high levels of resources to cases of every solvability class, there may be scope to improve detection rates, by allocating high, rather than low-medium resources to high and particularly medium solvability cases (Figure $3 \mathrm{~b}$ ). This suggests that conclusions that only $13 \%$ of burglaries can be solved (Eck, 1983; Paine \& Ariel, 2013) may be conservative. This should also strengthen explanation of detection in terms of resourcing and solvability. If solvability is poor, it is far more difficult to achieve detections by allocating extra resources than where cases are more solvable. Despite some low solvability cases where high resource inputs enable detection, it appears likely that many low solvability cases will be difficult, if not impossible to detect. It is also striking that little more than a third of high solvability cases allocated high resources were detected, so that most remained undetected, indicating that even cases graded here as 'high solvability', which were the best resourced third of cases, have insufficient evidence to always enable investigations that result in a positive outcome.

\section{RESOURCE USE IN INVESTIGATIONS}

Profiling the stage at which resources are input into incident responses and investigation indicates comparative resource effectiveness, helping identify where resources are better and more poorly aligned with solvability, and, hence, which resourcing decisions, respectively, enhance and diminish the prospects of burglary detection.

Figure 4. Mean resource time inputs per offence for investigative stages

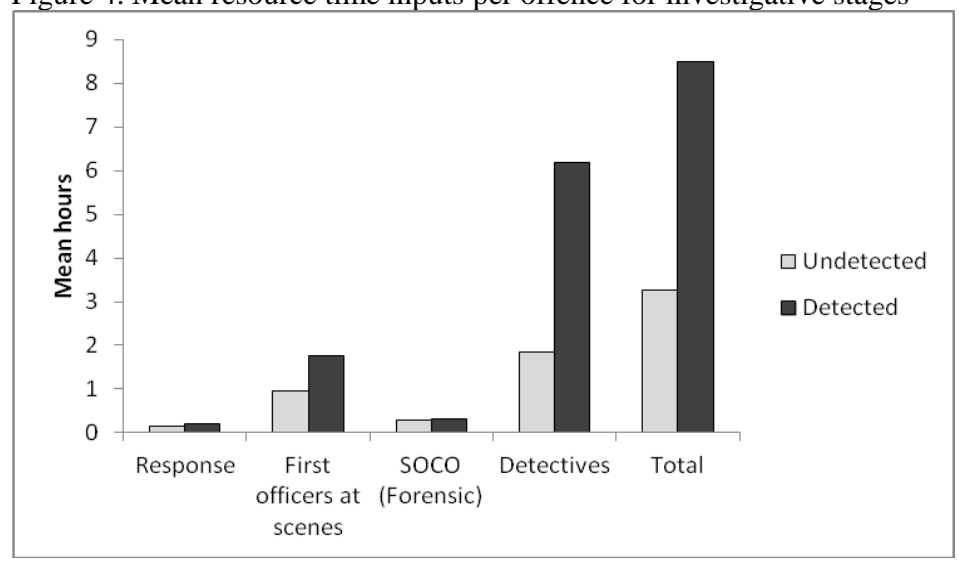


Figure 5. Total resource time inputs for the burglary population by investigative stage

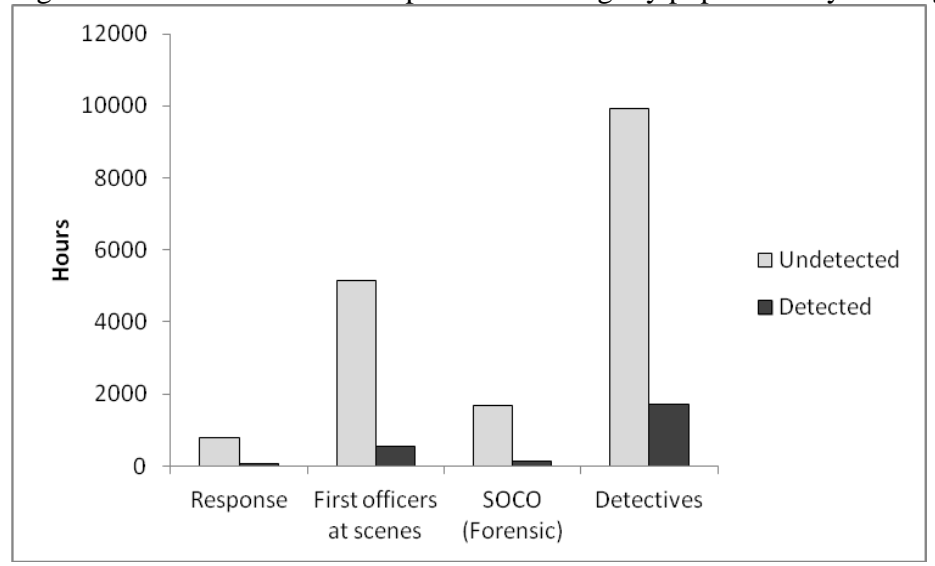

Largest time resources are used by detectives on both detected and undetected cases, both in terms of average per case (Figure 4) and for total spending on the population of burglary incidents (Figure 5), while crime scene work by first officers demanded the second highest amount of resources (Figures $4 \& 5$ ). To the extent that resource is mis-applied to unsolvable and undetected cases, these indicate where the scope for greater cost-effectiveness lies, by aligning staffing resources more closely with the most solvable subset of incidents at each investigative step. The least resources were spent on patrol response, but these comprised the combined response times of the officers who responded to each burglary incident; no other patrol time has been factored $\mathrm{in}^{4}$.

It appears that, for this sample, some resources used for detectives' further investigations might be better switched to first stage, 'front-end' activities, particularly if cases with better evidence can be identified. As much as the solvability characteristics that predict detection outcomes, greater cost-effectiveness appears to hinge on finding solvability factors to predict intermediate outputs relating to witness and forensic evidence that match those already identified for on/near scene capture (Coupe \& Blake, 2005), which can then drive resource allocation. It is on these that successful detection depends. Given the large amounts of time used for further investigations less cost-effectively than earlier police activities, better predictors of solvable cases are also needed at the investigative stage. By these means, it may be possible to re-balance the investigative system by redeploying resources at different investigative stages and address what appears to over-funding of detectives' time and under-funding of earlier police work.

\section{CONCLUSIONS}

Findings from this study support the idea that both solvability and resources affect detection levels, accounting for half the variation in detection outcomes. Incident solvability appears to be of greater importance, though findings indicate time resources account for at least a fifth of the combined substantive effect. This is a substantial level of explanation, particularly since data were collected in a peak year for crime when there were funding shortfalls, making it unlikely that all solvable case investigations were adequately resourced. Moreover, informal case screening procedures were operating in the different force command areas, so that resources may have been mis-directed to unsolvable cases, while promising ones were under-funded. It is likely that chance factors also played a part in explaining detection outcomes, down-grading effects due to solvability and resources. Evidence, therefore, suggests that solvability characteristics determine whether burglaries may be solved, but successful detection is contingent on resource inputs. Resources, therefore, enable the potential for detection due to solvability to be realised. Through the application of resources to cases via investigative activities, the evidence that enables detection is 'unlocked'. Solvability characteristics control whether cases can be detected and determine the amount of resource needed for detection.

Detections were generally higher for cases with high solvability and high resourcing, and lower if low solvability and low resourcing. Many low solvability cases appear virtually impossible to detect whatever 
resource is allocated. However, there were no categories of solvable cases, in this study covering the full solvability range, that did not contain some incidents capable of being detected, given sufficient resource, though more with better solvability characteristics were detected for every level of resource input.

Additional resources, therefore, boosted detection rates for all solvability levels, but more so for high solvability incidents, confirming, for the whole investigative process, existing findings about the arrest of burglars by patrols of different strength at incidents of varying solvability (Coupe \& Blake, 2005). This appears to be at odds with earlier studies (Eck, 1983; Brandl \& Frank, 1994) where more solvable cases needed fewer resources and investigations to solve them. It is likely that in Brandl \& Frank's (1994) study, as in this one, more solvable cases consumed less detectives' time, because of superior evidence from the prior application of first officer resources to investigative activities at burglary scenes. Equally, some of the third, least solvable burglaries in this study were, in the event, solved, whereas Eck (1983) and Brandl \& Frank (1994) concluded that this was not possible. This indicates that the strict application of triaging based on solvability would result in some detections being missed, so that officers should also 'follow the evidence' in such cases. In contrast, cases with poorer quality evidence from first stage activities that detectives assessed as having potential to be detected, subsequently required substantial further investigation, so that, as previously shown (Brandl \& Frank, 1994), detectives' caseloads included medium-solvability incidents that needed more resource per case and were less cost-effective to detect. Equally, on-scene arrest was frequently achieved with fewer resources.

This study demonstrates the benefits of examining the relationships between offence solvability, resources and detection outcomes. This approach would enable police services to monitor case investigation across investigative stages, offering potential to improve the match of resources to investigation of solvable cases and cost effective resource use. This may be expected to improve detections, as well as increase the importance of solvability and resources in explaining detection outcomes. Given shortfalls in resources needed to meet investigative demands of all solvable cases, such an approach can help inform screening decisions that prioritise case investigations and inform resource targeting.

Screening may also be improved by viewing investigation in terms of two key stages linked by intermediate outputs. This enables a distinction to be made between incident characteristics as direct predictors of detections and as predictors of the evidence upon which detection outcomes rest. Better solvability predictors for the policing activities that produce the intermediate outputs which result in detection, and for the cases where further investigation will result in sufficient evidence for detection, would be likely to facilitate better resource-solvability matching and a cost-effective increase in quantities of detected cases. The characteristics that make some 'in progress' burglaries more solvable than others are known (Coupe \& Blake, 2005). Equivalent indictors, for instance, of which neighbours at burglary targets are able to provide suspect descriptions, or which burglary scenes will provide useful forensic samples, are needed to target resources at the cases with evidence to be 'unlocked'.

This study has used data from the 1990s, but contemporary case screening is still reliant on experience rather than statistical analysis (Robinson \& Tilley, 2009), and the factors influencing burglary detection have changed little. On-scene capture and suspect identity evidence from witnesses still pre-dominate (Burrows, et al., 2005; Donnellan, 2012; Paine \& Ariel, 2013), although forensic evidence use, particularly DNA samples (Donnellan, 2012; Paine \& Ariel, 2013), has increased compared with the 1990s (Coupe \& Grifiths, 1996). It, therefore, seems likely that the substantive findings of this study will have some relevance to contemporary policing: it appears that first officers generate most evidence and do so most cost-effectively. However, the principal aims in this paper are to demonstrate the importance of incident solvability and resources in explaining detection outcomes and in framing the ways that different sorts of case are investigated, and to highlight the potential of an approach incorporating these factors for monitoring and improving cost-effective investigation.

Cases of quite varied solvability are detected, and this indicates that existing estimates of solvable cases may be conservative. More research is needed into how to identify the cases with evidence that may be 'unlocked' at different investigative stages using different activities. Additionally, understanding how incident solvability and resources affect the investigation and detection of other types of offences is needed to assess their wider applicability. Other crimes, such as serious assaults and the minority of difficult to solve 'who-done-it' homicides (e.g. Innes, 2002; 2007), may demand more resource intensive activities at 
the scene, while forensic evidence and detectives' further investigations may play a greater role. Measuring estate, back-office labour and equipment costs may improve accuracy, in so far as they differentially affect the investigation of different types of offences. It, nevertheless, seems likely that the implementation of statistically based crime screening will enable a better match of resources to offence solvability, so that more cases can be detected and detected more cost-effectively. The evidence presented here suggests that this will also enhance the role of solvability and resources in explaining detections.

\section{NOTES}

${ }^{1}$ Detected crimes are defined in the U.K. as having been cleared or ' solved' by the police (Home Office, 2008 ).

${ }^{2}$ These studies are based on data values aggregated by area, for instance, comparing average numbers of offences per officer or total numbers of offences for different areas, as opposed to studies that use data sets based on individual offences, such as this paper.

${ }^{3}$ SOCOs' average time at the scene was estimated using data from a complementary questionnaire survey of 200 burglary victims, randomly drawn from the full sample of incidents.

${ }^{4}$ Although detectives' further investigations appear to be the most demanding in terms of resource use, factoring in the full costs of maintaining patrols which responded to a mean of c. 6.9 incidents per patrol officer per day would elevate patrol response resource costs above those of detectives' further investigations. However, patrols also have other functions, whose draw on resources would need to be taken account of in some way.

\section{REFERENCES}

Ahlberg J (2002) Crime clearance and efficiency. An analysis of the factors affecting trends in the clear-up rate. Stockholm: National Council for Crime Prevention (BR $\AA$ )

Audit Commission (1993) Helping with Enquiries: Tackling Crime Effectively. London: HMSO.

Bradbury, S., Feist, A.(2005) The Use of Forensic Science in Volume Crime Investigations: A Review of the Research Literature. RDS Online Report 43/05. London: Home Office.

Brandl SG, Frank J (1994) The relationship between evidence, detective effort, and the disposition of burglary and robbery investigations. American Journal of Police, XIII, 3, 149-168.

Burrows J, Tarling R (1982) Detecting Crime. Home Office Research Study No. 73. London: HMSO.

Burrows J, Hopkins M, Hubbard R, Robinson A, Speed M, Tilley N (2005) Understanding the attrition process in volume crime investigations. Home Office research Study 295. London: Home Office Research, Development and Statistics Directorate.

Carden, R. (2012) Car key burglaries: An exploratory analysis. $5^{\text {th }}$ Cambridge Evidence-Based Policing Conference, 2012.

Chaiken, JM (1975) The criminal investigation process, Volume II: Survey of municipal and county police departments. Santa Monica, CA: Rand Corporation.

Cordner, GW (1989) Police agency size and investigative effectiveness. Journal of criminal Justice, 17, 3, 145-155.

Coupe RT, Griffiths M (1996) Solving residential burglary. Crime Detection and Prevention Series Paper 77. London: Home Office.

Coupe, RT \& Griffiths M (1999)The influence of police actions on victim satisfaction in burglary investigations. The International Journal of the Sociology of Law, Vol. 27, No. 4, December.

Coupe, RT \& Griffiths M (2000) Catching offenders in the act: an empirical study of police effectiveness in handling 'immediate response' residential burglary. The International Journal of the Sociology of Law, Vol 28, No. 2, June, 163-176.

Coupe RT, Kaur S (2005) The role of alarms and CCTV in detecting non-residential burglary. Security Journal, 18, 2, 53-72.

Coupe RT, Blake L (2005) The effects of patrol workloads and response strength on burglary emergencies. Journal of Criminal Justice 33 (3): 239-55.

Coupe RT, Blake L (2006) Daylight and darkness targeting strategies and the risks of being seen at residential burglaries. Criminology 44 (2):431-464. 
Coupe T (2014) An Evaluation of the Effects of Police Resources and Incident Solvability on Crime Detection. Legal Studies Research Paper No. 46/2014, August 2014. Faculty of Law, University of Cambridge. http://ssrn. com/abstract $=2481100$

Donnellan, G. (2012) Burglary solvability factors. $4^{\text {th }}$ Cambridge Evidence-Based Policing Conference, July, 2011.

Eck JE (1979) Managing case assignments: The burglary investigation decision model replication. Washington, DC: Police Executive Research Forum.

Eck JE (1983. Solving Crimes: The Investigation of Burglary and Robbery. Washington D.C: Police Executive Research Forum.

Greenberg B, Elliot CV, Kraft LP, Procter HS (1977) Felony Investigation Decision Model: An analysis of investigative elements of information. Washington D.C: National Institute of Law Enforcement and Criminal Justice.

Greenwood PW, Petersilia J (1975) The Criminal Investigation Process: Volume I: Summary and Policy Implications. Washington D.C : U.S. Government Printing Office, National Institute of Law Enforcement and Criminal Justice.

Innes, M. (2002) The 'Process Structures' of Police Homicide Investigations. British Journal of Criminology, 42, 669-688.

Innes, M. (2007) Investigation order and major crime inquiries. Chapter 10 in T. Newburn, T Williamson \& A. Wright (Eds) Handbook of Criminal Investigation. Cullompton, Willan.

Jansson K (2005). Volume crime investigations: A Review of the literature. Online Report 44/05. Home Office: London.

Johansson S (2012) Shift patterns and crime detection rates in a Swedish Police Department: An Exploratory analysis. Unpublished thesis, University of Cambridge.

Klinger DA (1997) Negotiating order in patrol work: An ecological theory of police response to deviance. Criminology, 35, 277-306.

Newburn, T. (2007) Understanding Investigation. Chapter 1, in T. Newburn, T Williamson \& A. Wright (Eds) Handbook of Criminal Investigation. Cullompton, Willan.

Newiss G (2002) Responding to and investigating street robbery. (Unpublished) Cited in Jansson K (2005). above.

Ostrom E (1976) On the meaning and measurement of output and efficiency in the provision of urban police services. In Munro J (Ed) Classes, conflict and control, 449-473. Cincinnati: Anderson Publishing.

Robb P., Coupe RT \& Ariel B. (2014) Solvability and detection of metal theft on railway property. Policing \& Society. In Press.

Ousey GC, Matthew RL (2010) To Know the Unkown: The Decline in Homicide Detection Rates, 19802000. Criminal Justice Review, 35, 2, 141-158.

Paine, C., Ariel, B. (2013) Solvability analysis: Increasing the likelihood of detection in completed, attempted and in-progress burglaries. $6^{\text {th }}$ Cambridge Evidence-Based Policing Conference, 2013.

Paré P, Felson RB, Ouimet M (2007). Community Variation in Crime Detection: A Multilevel Analysis with Comments on Assessing Police Performance. Journal of Quantitative Criminology, 23, 243-258.

Roberts A (2008) The influences of incident and contextual characteristics on crime detection of nonlethal violence: A multilevel event history analysis. Journal of Criminal Justice, 36, 1, 61-71.

Robinson A, Tilley N (2009) Factors influencing police performance in the investigation of volume crimes in England and Wales. Police Practice and Research: An International Journal, 10, 3, 209-223.

Taylor P, Chaplin R (2011) Crimes Detected in England and Wales 2010/11. Statistical Bulletin, 10/11. London: Home Office.

Tilley, N \& Ford,A.(1996) Forensic Science and Crime Investigation. Crime prevention and detection Series Paper 73, London: Home Office.

Tilley N, Burrows, J.(2005) An overview of attrition patterns. Online Report 45/05. London: Home Office. Tilley, N., Robinson, A. \& Burrows, J. (2007). The investigation of high volume crime. Chapter 9, in T.

Newburn, T Williamson \& A. Wright (Eds) Handbook of Criminal Investigation. Cullompton, Willan.

Welford C, Cronin J (1999). An Analysis of Variables Affecting the Detection of Homicides: A

Multivariate Study. Washington, DC: Justice Research Statistics Association.

Williams V, Sumrall R (1982) Productivity Measures in the Criminal Investigation Function. Journal of Criminal Justice, 10, 2, 111-122. 